\title{
Validity and Reliability of The Turkish Version of Fear of Cancer Recurrence Inventory
}

\section{Aslı EYRENCi,' $\odot$ Hanife Özlem SERTEL BERK²}

Department of Psychology, Maltepe University, Istanbul-Turkey Department of Psychology, Istanbul University, Istanbul-Turkey

\section{OBJECTIVE}

The aim of this study is to conduct the Turkish adaptation and to test the validity and reliability of the Turkish version of the "Fear of Cancer Recurrence Inventory (FCRI)."

\section{METHODS}

A total of 219 mixed-type cancer survivors with a mean age of 50.76 years participated in the study (79.9\% women). They were asked to complete the Impact of Events Scale (IES) and Patient Health Questionnaire-Somatic Anxiety, and Depressive Symptoms (PHQ-SADS) along with the translated versio of FCRI.

\section{RESULTS}

By exploratory factor analysis and oblique rotation, the number of factors of the original scale decrease from 7 to 5 and three of them have been renamed ("recurrence-related meta-cognitions," "emotion-focused coping strategies," and "quality of life"). The overall Cronbach's alpha coefficient of FCRI was 0.94 and the item-total correlations ranged between 0.37 and 0.75 . With respect to concurrent validity, except for the "avoidance" subscale of IES, significant correlations $(\mathrm{r}=0.13-0.70$; all $\mathrm{p}<0.01)$ were found between

\section{CONCLUSION}

The Turkish version of FCRI has satisfactory psychometric properties, and it is eligible for use in studies in Turkey.

Keywords: Fear of cancer recurrence; fear of cancer recurrence inventory; cancer.

Copyright @ 2018, Turkish Society for Radiation Oncology

\section{Introduction}

Cancer is still a disease with an increasing prevalence and is one of the major causes of death; however, there is an increase in the duration and survival rates of patients with cancer due to advances in its treatment modalities. [1] In Turkey, according to the reports of a screening study conducted in $2014,51.6 \%$ of the patients with cancer survived.[2] There are approximately

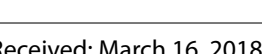

32.6 million surviving patients with cancer worldwide. [3] This increase in the duration and survival rates may conversely lead to some psychosocial problems, e.g. fear of recurrence.[4] Although there are various definitions in the literature, the most frequently used definition for fear of recurrence is the fear or worry about whether cancer will recur or progress in the same or a different part of the body.[5]

According to various research, it has been observed

Ars. Gör. Assl EYRENCI
Maltepe Unniversitesi, Psikoloji,
Istanbul-Turkey
E-mail: aslieyrenci@maltepe.edu.tr

that among the patients with different kinds of cancer, $39 \%-97 \%$ of them have experienced fear of cancer recurrence (FCR) to a certain extent, $22 \%-87 \%$ experienced FCR at a rate increasing from moderate to high levels, and 0\%-15\% experienced FCR at a high level. [6] It has also been observed that FCR is quite common among patients with breast, ovarian, colon, lung, and prostate cancers, and it continues for a long time even after the end of the treatment, reduces the quality of life, causes disruptions in the level of adjus qualxiety, and negatively ffects the ability to make future plans.[4,5,7] Additionally, FCR also leads to the concern that the medical treatment being provided is inadequate, which consecutively may increase the overutilization of medical services and thus medical expenses.[6,8] Literature also highlights several predictors and/or correlates of FCR, which are demographic (female sex, younger age, and low level of education), medical (shorter duration fter being diagnosed with cancer, the severity of trentanter being ing ox (t) the high intensity of pain and physical symptoms), and psychological (curre
sive disorders). [6,9]

In the literature, it is mentioned that although low
sive disorders. $[6,9]$ levels of FCR result in emotional reactions that may be defined as normal and temporary and provides being alert against a potential threat or enables one to perform some protective and preventive health behaviors high levels of FCR can end up in unrealistic, frequently epeated and continuous intrusive thoughts, provoke a continuous seeking for security, or cause impairments in functionality. $[10,11]$ Conversely, the limited number of studies examining the relation between FCR severity and long-lasting psychopathological disorders and psychological morbidity have reported that the fear of recurrence meets the criteria for clinical level of generalized anxiety disorder in patients with breast [12] and prostate cancer.[13] Then again, Simard, Savard, and vers [14] showed in their study that while the intrusive thoughts red to FCR have many come intrusive houghts rear eristics with the concens specific to generalized anxiety disorder, these thoughts show rather the characteristics of obsessive compulsive disorder, in the situations with high level of FCR. Regarding the relation between FCR and depression and anxiety, while the direction is not clear, there seems to be a stronger relation in comparison with the other emotional disorders. [9]

Although there are many measurement tools in the literature for evaluating FCR according to a systematic review study by Thewes, Butow, Zachariae, Chris- tensen, Simard, and Gotay, wherein they evaluated elf-reported measures that measure FCR, it was concluded that FCRI [9] is an effective measurement too among the existing ones, with respect to psychometric characteristics.[11] FCRI has been developed based on the FCR model of Lee-Jones, Humphris, Dixon and Hatcher [15] in a cognitive-behavioral framework based on the model that includes the triggers and outcomes of and cognition and emotions accompanying FCR on one hand and the diagnostic criteria of anxiM-IV [16] on the

In our country, the number of studies on FCR is limited. Moreover, no measurement tool for evaluating FCR and the outcomes of this fear have been reported. Therefore, considering Thewes and colleagues suggestions on FCRI [11] and the inventory's multidimensional nature, in this study, FCRI was chosen for its adaptation in Turkish. FCRI can be applied to mixed cancer groups as it comprehensively evaluates the trigvaluates the triggers, intensity, frequency, and psychological and physigical effects of FCR in various dimensions.

Therefore, the major aim of his study was to conduct the Turkish adaptation of FCRI and to investigate whether FCRI is a valid and reliable tool for measuring FCR in a group of cancer survivors. In this respect, it is firstly expected that FCRI will demonstrate an acceptable factor structure that is close to its original version and similar internal consistency values. Within the scope of the construct validity, a positive significant re scope of the con $\mathrm{F}$. thession is expected, in the light of the findings of the abovementioned literature. Moreover, a similar trend of relationship is also proposed with intrusive thoughts accompanying or preceding anxiety and depression and with levels of hyperarousal, somatization, and avoidance, where the latter three can be evaluated as the outcomes of these intrusive thoughts and affective reactions of anxiety and depression.

\section{Materials and Methods}

\section{The Sample Group}

The sample of the research consisted of patients with mixed-type cancer who had completed their primary oncology treatment (chemotherapy, radiotherapy, surgery) and who continued with their routine follow-ups at Medical Oncology Polyclinic, Cerrahpasa Medical Faculty Hospital, Istanbul University. Patients who continued their cancer treatment and who were not mentally suitable to be tested using the scales were ex- 
cluded. Totally, data was collected from 219 patients. The mean age of patients was 50.76 years $(n=219$, $\mathrm{SD}=12.50) ; 79.9 \%(\mathrm{n}=175)$ were women and $53 \%$ had been diagnosed with breast cancer $(n=116)$. The most common types of cancer after breast cancer $(n=116)$ were gastrointestinal cancer $(14.2 \% ; n=31)$, gynecologic cancer $(7.8 \% ; \mathrm{n}=17)$, and genitourinary cancer $(5 \%$; $\mathrm{n}=11)$. Of the participants, $45.2 \%(\mathrm{n}=99)$ were primary school graduates. The percentage of the participants who received chemo prapy was $78.1 \%(n=171)$ and who revis (ne treatment of nearly half of the patients, $48.9 \%(\mathrm{n}=107)$ was completed $0-2.5$ years ago, and $32 \%(\mathrm{n}=70)$ of them continued with their follow-up appointments once every 6 months.

\section{MEASURES}

Fear of Cancer Recurrence Inventory

FCRI, originally developed in French by Simard and Savard [9] for patients with breast, colon, prostate, and lung cancer, was adapted in English by Lebel, Simard, Harris, Feldstain, Beattie, McCallum, Lefebvre, Savard, and Devins.[17] In this study, the English version of the scale was used for the Turkish adaptation. It consists of 42 items with seven subscales:

Triggers: Includes nine items about medical examinations and television shows or newspaper articles on cancer, which may act as triggers for FCR and thereby are attempted to be avoided.

Severity: Includes nine items for assessing the perceptions about the frequency, intensity, and duration of FCR-perceived risk of recurrence and the beliefs in the degree of normality of concerns about the risk of recurrence.

Psychological Distress: Includes four items that test four different emotions including anger, sadness, helplessness, and anxiety that can be triggered by FCR

Coping Strategies: Includes nine items where the frequency of several coping strategies related to FCR are evaluated [e.g "I try to distract myself (do various ctivities, watch television, read, work)" the hink abor

Functioning Impairments: Includes six items that investigate functional impairments in the capacity to make future plans or to set life goals in social or leisure time activities due to FCR.

Insight: Three questions measure the degree of perceptions in patients regarding the excessiveness or irrationality of their fears.

Reassurance: Assesses the frequency of reassurance or help-seeking behaviors related to FCR (e.g., "I exam- ine myself to see if I have any physical signs of cancer" and "I go to the hospital or clinic for an examination"). FCRI, is a Likert-type scale that ranges from 0 (not at all/never) to 4 (all the time/a great deal). Increasing scores received from the scale demonstrate a high level of FCR.

The English version of the scale has similar psychometric characteristics (For total scale scores, $\alpha=0.96$ for test-retest $r=0.88$ ) [17] In the French version of FCRI while "intusion" (r=0.66, $p<0.001)$ and "the (1) (Eventy" $(\mathrm{r}=0.64, \mathrm{p}<0.001)$ subscale of Hospital Anxiety and De pression Scale (HADS) [19] were found to have strong significant relations with FCRI total score, a moderate correlation with "the depression" $(\mathrm{r}=0.43, \mathrm{p}<0.001)$ subscale of HADS was obtained.[17]

\section{Turkish Version of FCRI}

After getting necessary permissions for the Turkish adaptation on October 11, 2015 from Sébastien Simard, one of the authors of the scale, the following steps were followed for adapting the scale: First, the scale was translated to Turkish by three English Linguists who had a command over Turkish and English. Next, the three translated versions were evaluated by two academicians who had a comprehensive knowledge of the field, in terms of convenience through a 5-point Liker scale for each item, and these experts suggested changes, if any. The average of the items was calculated for each translation, and the translation with the highest score was included in the scale. This form of the scale was independently evaluated in terms of language convenience by two Turkish philology experts, again using a 5-point Likert scale of convenience. After all these steps, the Turkish translation of the scale was put into the final form and administered to a pilot sample who evaluated the comprehensibility of the instructions, items, and response scale and provided suggestion for revision, if any, again using a 5-point Likert scale. The pilot samp consisted of 10 patients with cancer who were approached by a snowb ing metho and whose primary cancer treatments were completed (breast cancer, $\mathrm{n}=7$; gynecologic cancer, $\mathrm{n}=1$; genitourinary cancer, $n=1$; and skin cancer $n=1$ ). All the participants at the pilot step verbally stated that the scale was clear and comprehensible. The convenience mean of each item was calculated as at least $\geq 3$ at each step, and the back translation of the scale was done by two experts different from those at the first step who also had a command over the language. The back-translated text was sent to the authors of the original version, and the adaptation study was started after receiving their approval.

\section{Demographic and Medical Information Form}

Besides the demographic variables, information concerning medical status (type of cancer, radiotherapy chemotherapy completion time, follow-up frequency etc.) was also questioned.

Patient Health Questionnaire-Somatic, Anxiety, and Depressive Symptoms

Originally developed by Kroenke, Spitzer, and Williams [20], the Turkish adaptation and validity-reliability study of PHQ-SADS was performed by Güleç, Güleç, Şimşek, Turhan, and Sümbül.[21] This questionnaire was used to measure the concurrent validity of FCRI in this study. There are 37 items which evaluate the severity of the symptoms of somatization, anxiety and depression, and pynic disorder. It was found that the scele, with an ency Cronbach alpha coefficient of 0.93. [21]

\section{Impact of Events Scale-Revised}

In the literature, having been diagnosed with a type of cancer is acknowledged as a traumatic experience, which is known to end up with several psychological symptoms [22] Therefore, to evaluate the traumatic stress symptoms in this study, IES-R, developed by Weiss and Marmar [18], was used to evalute the con weiss and Martity of the FCR scale. The validity concurrent valdity on of IES-R were performed by Çorapçıŏlu, Yargıç, Geyran, and Kocabaşoğlu.[23] The scale consists of 22 items and three subscales (avoidance, intrusion, and hyperarousal), and the frequency and severity of each symptom was measured through a 5-point Likert scale $(0-4)$. Other validity values of the scale were reported to be adequate. The Cronbach internal consistency coefficient of the scale was found as 0.93 . [23]

\section{Procedure}

After getting the ethical committee approval of İstanbu University Ethical Committee of Social and Human Scientific Studies on February 25, 2016, the adaptation study was started; $92.7 \%(n=203)$ of the participant filled in the batteries using a paper and pencil, and the rest of them provided data by the online method. Among the paper and pencil sample, $29.2 \%(n=64)$ of Ame participants filled in the batteries on an individual basis, whereas $70.3 \%(n=154)$ performed the adminis- tration after the researcher had read the questions. The implementations performed with the paper and pencil method took about $30 \mathrm{~min}$. The data were combined as no significant difference was observed $(\mathrm{t}(200)=-1.62$, $\mathrm{p}>0.05)$ between the mean FCRI scores of the participants who filled in the batteries individually $(\mathrm{M}=36.77$, $\mathrm{SD}=21.13$ ) and those who filled in with the help of the researcher $(\mathrm{M}=30.95, \mathrm{SD}=21.83)$.

\section{Data Analysis}

First, an item analysis was conducted to determine the discriminative values of the scale items. To test for the construct validity of the scale, an exploratory factor analysis with principal axis factoring method and oblique rotation were implemented. Both the item and factor analysis were conducted among the whole sample regardless of the cancer type, as to the sample size criteria of item number X minimum five subjects.[24] For further test of construct validity, both in the whole sample and among the largest subsample of patients with breast cancer separately, the inter-correlations of the whole scale and its factors obtained from the factor analysis were tested, whereas their relations with the other scales were investigated for its concurrent validity through calculating Pearson's product-moment correlation coefficients. To compare the goodness of fit (GFI) of the factor structures of the obtained model and the original model, a confirmatory factor analysis was performed using LISREL 8.51 software in the whole sample and among patients with breast cancer. The reliability of the scale was examined using Cronbach's alpha coefficient.

\section{Results}

\section{Factor Analysis}

As a result of the item analysis, five items $(31,37,39,40$ 41 ), with an item-total score correlation of $<0.20$, were excluded, and the remaining 37 items were subjected to factor analysis. During the factor analysis, items whose communality values (item numbers: $4,8,9,11,13,14$ $32,33,38$ ) and factor loadings (item numbers: 35,36 $12,42)$ were $<0.30$ were removed from the scale. The final analysis with the remaining 24 items revealed a 5 -factor structure with eigenvalues $>1$ that explained $64.9 \%$ of the total variance, which were named as "triggers," "functioning impairments," "recurrence-related meta-cognitions," "emotion-focused coping strategies, and "quality of life."

The first factor of the scale, "triggers," consisted of seven items that explained $43.3 \%$ of the total variance.

The second factor named "functioning impair- 
Table 1 Factors, items, factor loading, and common variance obtained after oblique rotation

\section{Factor/tem}

Factor Loading

Communality

Triggers, 7 items, Eigenvalue: 10.83 , Variance: $43.34 \%$

2 An appointment with my doctor or other health professional

3 Medical examinations (e.g. annual check-up, blood tests, $X$-rays)

Seeing or hearing about someone who is il

Television shows or newspaper articles about cancer or illnes

Going to a funeral or reading the obituary section of the pap

When I feel unwell physically or when I am sick

10 I am afraid of cancer recurrence

Functioning Impairments, 2 items Eigenvalue: 2.05, Variance: $8.2 \%$

22 My social or leisure activities (e.g. outings, sports, travel)

23 My work or everyday activities

Recurrence Related Meta-Cognitions, 4 items. Eigenvalue: 1.17, Variance: $4.71 \%$

15 How often do you think about the possibility of cancer recurrence?

17 How long have you been thinking about the possibility of cancer recurrence?

28 I feel that I worry excessively about the possibility of cancer recurrence

Emotion-Focused Coping Strategies, 5 items. Eigenvalue: 1.15, Variance: $4.63 \%$

19 Sadness, discouragement or disappointment

20 Frustration, anger or outrage

18 Worry, fear or anxiety

21 Helplessness or resignation

34 I try to distract myself (e.g. do various activities, watch television, read, work)

Quality of Life, 6 items. Eigenvalue: 1, Variance: $4.01 \%$

26 My state of mind or my mood

27 My quality of life in genera

25 My ability to make future plans or set life goals

24 My relationships with my partner, my family, or those close to $m e$

30 I think that I worry more about the possibility of cancer recurrence than other people

who have been diagnosed with cancer

29 Other people think that I worry excessively about the possibility of cancer recurrence

\begin{tabular}{ll}
.75 & .54 \\
.66 & .55 \\
.66 & .62 \\
.57 & .59 \\
.40 & .50 \\
.43 & .47 \\
.39 & .61 \\
& .75 \\
.72 & .82 \\
& .77 \\
-.73 & .65 \\
-.71 & .62 \\
-.57 & .50 \\
-.41 & .58 \\
-.81 & .77 \\
-.74 & .63 \\
-.53 & .61 \\
-.51 & .52 \\
-.38 & .20 \\
.74 & .76 \\
.66 & .67 \\
.61 & .54 \\
.46 & .36 \\
.43 & .53 \\
.36 & .38 \\
& \\
\hline &
\end{tabular}

ments" included two items and it explained $8.2 \%$ of the total variance.

In the third factor, there were four items that explained $4.7 \%$ of the total variance. In this factor, item number 28 which was in the "insight" factor, and the items numbered 15,16 , and 17 , which were in the "severity" factor, in the original scale were gathered under one factor and called as "recurrence-related meta-cognitions."

The fourth factor consisted of five items and it constituted $4.6 \%$ of the variance. As the items were considered to represent emotion-focused coping strategies, the name "emotion-focused coping strategies" was given to the factor.

In the 5th factor, while item 30 and 29 were in the "insight" factor in the original scale, these two have been loaded together with the items that were in the "functioning impairments" factor in the original scale. In this case, as all the items in the 5th factor were thought to represent features related to quality of life, this factor was named as "quality of life," which included a total of six items and constituted $4.01 \%$ of the total variance.

The Cronbach's alpha coefficient obtained from the FCRI total scale was 0.94 , and the item-total score bach's coefficient for "triggers," "functioning impairments," "recurrence-related meta-cognitions," "emotion-focused coping strategies" and "quality of life" 83 , and 0.84 respectively. The item-total score correlations varied in "triggers" factor between 0.61 and 0.73 in "recurrencerelated metacognitions" factor between 0.58 and 0.70 in "emotion-focused coping strategies" factor between 0.40 and 0.75 and in "quality of life" factor between 0.48 and 0.74. In "functioning impairments" subscale, the Cronbach's coefficient value for both items was 0.81 . Finally, the mean FCRI score was found as correlations varied between 0.37 and 0.75 . The Cron-
Table 2 CFA results of the Turkish and original versions of FCRI (whole sample and breast cancer sample)

\begin{tabular}{lcccc} 
& $\begin{array}{c}\text { Turkish Version of } \\
\text { FCRI with } 5 \text { Factors } \\
\text { (Whole Sample) }\end{array}$ & $\begin{array}{c}\text { Original Version of } \\
\text { FCRI with 7 Factors } \\
\text { (Whole Sample) }\end{array}$ & $\begin{array}{c}\text { Turkish Version of } \\
\text { FCRI with 5 Factors } \\
\text { (Breast Cancer Sample) }\end{array}$ & $\begin{array}{c}\text { Original Version of } \\
\text { FCRI with 7 Factors } \\
\text { (Breast Cancer Sample) }\end{array}$ \\
\hline $\mathrm{X}^{2} / \mathrm{df}$ & 1.99 & 1.82 & 2.20 & 1.88 \\
RMSEA & .067 & .062 & .095 & .078 \\
GFI & .85 & .76 & .74 & .64 \\
CFI & .92 & .84 & .84 & .73 \\
ECVI & 15.35 & 22.89 & 5.30 & 13.61 \\
AIC & 3346.44 & 4988.88 & 2131.20 & 3569.71 \\
\hline
\end{tabular}

$\mathrm{SD}=21.5$. Factors, items, and psychometric properties of the Turkish version of FCRI are presented in Table 1 (See for the Turkish version of the items by the factors)

As the largest subsample of the whole participants consisted of patients with breast cancer $(n=116)$, before advancing in further analysis, an independent samples t-test was conducted to investigate whether FCRI scores obtained from the Turkish version changed as a function of cancer type where the patients with breast cancer were compared with the rest of the sample. It was observed that the two cancer groups did not differ in any of the scores measured using the Turkish version of FCRI $(\mathrm{t}(217)=0.96, \mathrm{p}>0.05$ for the total FCRI score (217) $=0.16, p>0.05$ fo $\mathrm{FCRT}$ the tot $p>0.05$ for "functioning impairments"; $t(217)=1.49$, $\mathrm{p}>0.05$ for "recurrence-related meta-cognitions"; $\mathrm{t}(217)=1.56, \mathrm{p}>0.05$ for "emotion-focused strategies" $t(217)=1.09, p>0.05$ for "quality of life"). Therefore, in the rest of the results section, the analysis run for the whole sample (the breast cancer sample and the other type cancer sample combined) and solely for the breast cancer subsample are presented.

Accordingly, a further analysis was conducted for patients with breast cancer. The Cronbach's alpha coefficients for this subsample were 0.94 for FCRI total scale, 0.88 for "trigger," 0.82 for "functioning impairments," 0.81 for "recurrence-related meta-cognitions," 0.82 for "emotion-focused coping strategies" and 0.80 for "quality of life" subscales. Item-total correlations varied between 0.34 and 0.77 . Moreover, the mean FCR score was $\mathrm{M}=34.33, \mathrm{SD}=22.2$.

\section{Confirmatory Factor Analysis}

Confirmatory factor analysis (CFA) was performed to compare the original factor model of the scale and the factor model obtained from the Turkish version in the whole sample. A further CFA was done among breast cancer subsamples as well. The models were tested using the maximum likelihood estimation method. The acceptable fit indices criteria were expected to be $<5$ for the proportion of the chi-square to degrees of freedom $\left(\chi^{2} / \mathrm{df}\right),>0.90$ for GFI and comparative fit index (CFI) [25], and $<0.08$ for root mean square error of approximation (RMSEA) [26] Finally, when a comparison was made between models, the mode with the lower expected cross validity index (ECVI) and Akaike's information criterion (AIC) was considered to be more preferable.[27] The fit indices of the Turkish version and those obtained from the original version of FCRI for the whole sample and breast cancer subsample are summarized in Table 2 . The path diagrams obtained from CFA of the Turkish version and the original version for the whole sample are presented in Figure 1 and Figure 2, respectively.

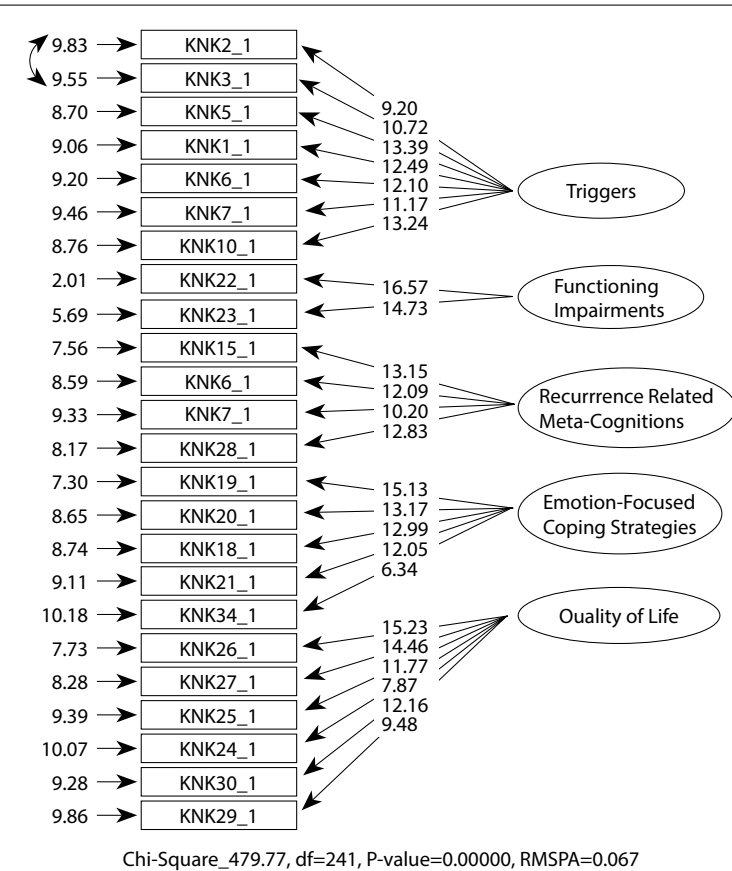

Fig. 1. Path diagram of the Turkish version of FCRI 
Table 3 Descriptive statistics, Cronbach's a coefficients, and intercorrelations between factors, total score and validity scales $(n=21)$

\begin{tabular}{|c|c|c|c|c|c|c|c|c|c|}
\hline Measures & M & SD & $a$ & 1 & 2 & 3 & 4 & 5 & FCRSum \\
\hline \multirow[t]{2}{*}{ IES-R (Intrusion) } & 9.73 & 6.95 & .85 & $.60^{* *}$ & $.45^{* *}$ & $.62^{* *}$ & $.55^{* *}$ & $.62^{*}$ & $.70^{* *}$ \\
\hline & 10.32 & 7.07 & .87 & $.60^{* *}$ & $.56^{* *}$ & $.63^{* *}$ & $.58^{* *}$ & $.67^{* *}$ & $.72^{* *}$ \\
\hline \multirow[t]{2}{*}{ IES- R (Avoidance) } & 15.68 & 5.90 & .62 & .06 & .04 & .06 & $.13^{*}$ & $.15^{*}$ & .12 \\
\hline & 15.70 & 5.58 & .62 & .05 & .07 & .07 & .1 & $.19^{*}$ & .12 \\
\hline \multirow[t]{2}{*}{ IES- R (Hyperarousal) } & 7.27 & 5.76 & .76 & $.47^{* *}$ & $.44^{* *}$ & $.46^{* *}$ & $.48^{* *}$ & $.56^{* *}$ & $.59^{* *}$ \\
\hline & 8.14 & 6.30 & .77 & $.47^{* *}$ & $.56^{* *}$ & $.50^{* *}$ & $.49 * *$ & $.60^{* *}$ & $.61^{* *}$ \\
\hline \multirow[t]{2}{*}{ PHQ-15 (Somatization) } & 9.14 & 5.97 & .84 & $.30 * *$ & $.34^{* *}$ & $.33^{* *}$ & $.26^{* *}$ & $.41^{* *}$ & $.39^{* *}$ \\
\hline & 10.09 & 6.12 & .83 & $.26^{* *}$ & $.43^{* *}$ & . $39 * *$ & $.28^{* *}$ & $.48^{* *}$ & $.41^{* *}$ \\
\hline \multirow[t]{2}{*}{ PHQ-9 (Depression) } & 6.66 & 6.07 & .74 & $.38^{* *}$ & $.42^{* *}$ & $.36^{* *}$ & $.37 * *$ & $.44^{* *}$ & $.47^{* *}$ \\
\hline & 7.20 & 5.90 & .71 & $.37 * *$ & $.46^{* *}$ & $.45^{* *}$ & $.40^{* *}$ & $.47^{* *}$ & $.49^{* *}$ \\
\hline \multirow[t]{2}{*}{ GAD-7 (Anxiety) } & 5.89 & 5.12 & .85 & $.50 * *$ & $.47^{* *}$ & $.54 * *$ & $.49 * *$ & $.55^{*}$ & $.62^{* *}$ \\
\hline & 6.33 & 5.22 & .72 & $.52^{* *}$ & $.55^{* *}$ & $.57^{* *}$ & $.47^{* *}$ & $.58^{* *}$ & $.63^{* *}$ \\
\hline \multirow[t]{2}{*}{ 1. Triggers } & 12.03 & 7.72 & .88 & - & $.40^{* *}$ & $.66^{* *}$ & $.68^{*}$ & $.60^{* *}$ & $.87^{* *}$ \\
\hline & 12.11 & 7.84 & .88 & & $.43 * *$ & . $71 * *$ & $.71 * * *$ & $.61 * *$ & $.88^{* *}$ \\
\hline \multirow[t]{2}{*}{ 2. Functioning Impairments } & 1.2 & 2.2 & .90 & $.40^{* *}$ & - & $.40^{* *}$ & $.47^{* *}$ & $-.65^{*}$ & $.63^{* *}$ \\
\hline & 1.07 & 1.99 & .82 & $.43^{* *}$ & & $.47^{* *}$ & $.54^{* *}$ & $.73^{* *}$ & $.68^{* *}$ \\
\hline \multirow[t]{2}{*}{ 3. Recurrence Related Meta-Cognitions } & 4.8 & 3.88 & .80 & $.66^{* *}$ & $.40^{*}$ & & $.64^{*}$ & $.59^{*}$ & $.80^{* *}$ \\
\hline & 5.18 & 3.91 & .81 & $.71 * *$ & $.47^{* *}$ & & $.70^{* *}$ & $.61^{* *}$ & $.83^{* *}$ \\
\hline \multirow[t]{2}{*}{ 4. Emotion- Focused Coping Strategies } & 9.02 & 5.54 & .83 & $.68^{* *}$ & $.47^{* *}$ & $.64^{* *}$ & - & $.63^{* *}$ & $.85 * *$ \\
\hline & 9.57 & 5.46 & .82 & . $71 * *$ & $.54 * *$ & $.70^{* *}$ & & & $.67^{* *}$ \\
\hline \multirow[t]{2}{*}{ 5. Quality of Life } & 6.02 & 6.38 & .84 & $.60^{* *}$ & $.65^{* *}$ & $.59^{* *}$ & $.63^{* *}$ & - & $.85^{* *}$ \\
\hline & 6.47 & 6.80 & .80 & $.61^{* *}$ & $.73^{* *}$ & $.61^{* *}$ & $.67 * *$ & & $.86^{* *}$ \\
\hline
\end{tabular}

$*^{* *} p<.01,{ }^{*} p<.05$
Italic values belong to the breast cancer subgroup and the others belong to the whole group

In accordance with the criteria mentioned, both for the whole sample and breast cancer subsample, although the RMSEA and $\chi^{2} / \mathrm{df}$ value of the original version was below the values obtained in the Turkish version, CFI and GFI values were higher in the Turkish version of FCRI. Moreover, as the ECVI and AIC values of the 5-factor model were lower, it is possible to say that the data fits the Turkish version of the scale better than the original version.

\section{Concurrent Validity}

To test the concurrent validity of FCRI within the scope of construct validity, PHQ-SADS and IES-R were used. The descriptive statistics of FCRI and its subscales, PHQ-SADS subscales and IES-R subscales, and the intra-correlations of FCRI sub-tests and their inter-correlations with the concurrent validity scales for both the whole sample and the breast cancer subsample are presented in Table 3 .

For the whole sample, the highest correlation with FCRI total score was obtained for "intrusion" subscale of IES-R $(r=0.70, p<0.01)$. As observed in the original study of FCRI, low to moderate significant correlations were found between the Turkish version of FCRI's subscales and the total score and all the subscales of IES-R (between $r=0.12$ and $r=0.59$ ), except for the "avoidance" subscale. The correlations of "avoidance" subscale of IES-R with the other factors, except for the "emotion-focused coping strategies" and "quality of life" of FCRI, were insignificant.

There were significant relations between all the FCRI subscales and PHQ-SADS subscales. Among the subscales of PHQ-SADS, "GAD-7 (anxiety)" showed the highest and "PHQ-15 (somatization)" showed the lowest correlation with FCRI total score. High correlations were also observed between "GAD-7 (anxiety)" and "quality of life" $(r=0.55, p<0.01)$ and "recurrencerelated meta-cognitions" $(\mathrm{r}=0.54, \mathrm{p}<0.01)$ subscales of FCRI. Finally, there was a significant relationship between "PHQ-9 (depression)" subscale and FCRI total score $(r=0.47, p<0.01)$ and all the subscales $(r=0.36-0.44$ $\mathrm{p}<0.01)$. As for the breast cancer subsample, a trend similar to that of the whole was obtained for sample interand intra-correlations, as can be seen at Table 3 .

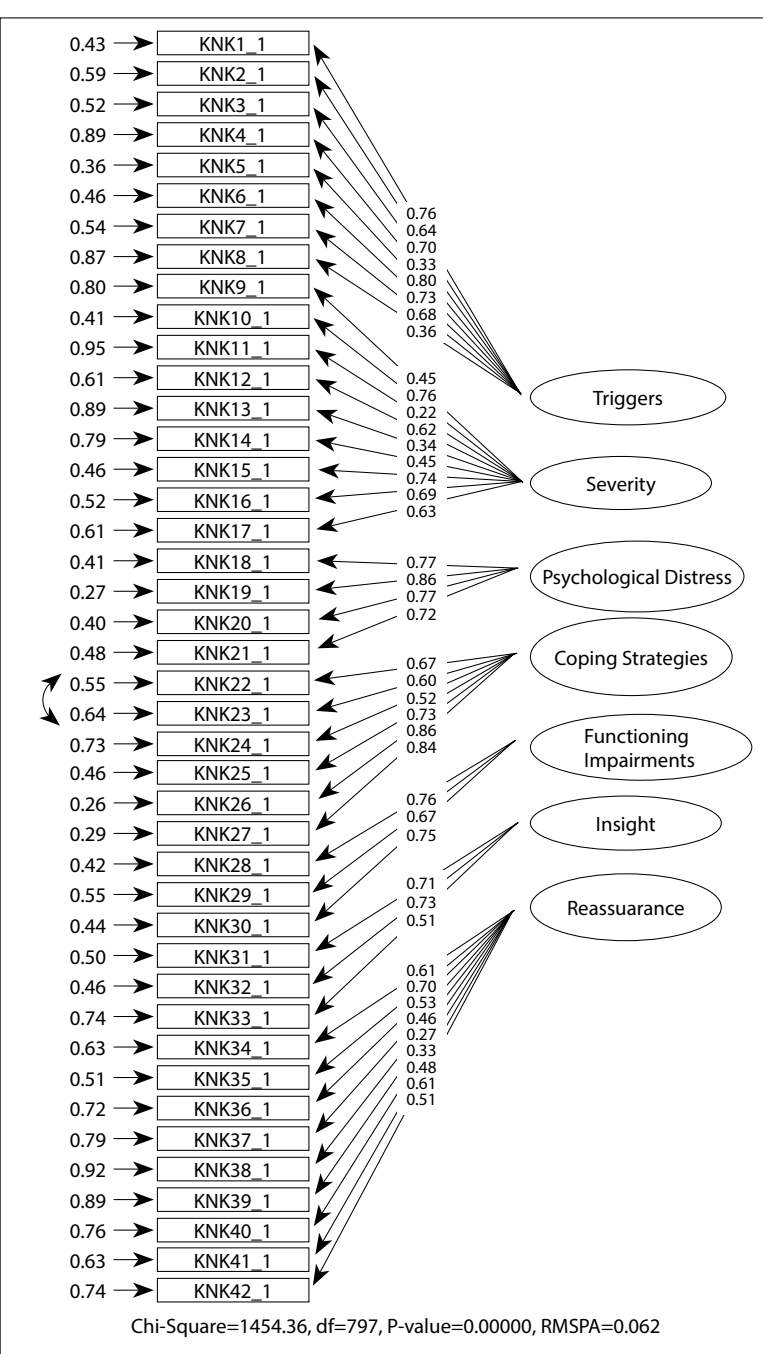

Fig. 2. Path diagram of the original version of FCRI.

\section{Discussion}

In this study, the validity and reliability of the Turkish version of FCRI, originally developed by Simard and Savard [9], was performed to measure FCR, which is one of the most frequently observed problems among patients with cancer who have completed their treatment. The exploratory factor analysis revealed a 5 -factor structure with a total of 24 items that explained $64.9 \%$ of the total variance. "Reassurance," "severity," and "psychological distress" factors from the original scale no longer existed as distinct factors in the new form of the scale, but some items of these originally emerging subscales were loaded under different factors in the Turkish version. Apart from these, although "triggers," "functioning impairments," and "coping "strategies" subscales of the original version seemed more or less to be remaining as distinct factors in the
Turkish version as well, to a certain extent, they differed from the original scales in terms of the content or number of items. The differentiation in the new factor structure compared with the original version has been discussed following the factor order.

In "triggers" factor, which is also the first factor in the original scale, six of the items from the original subscale that question the triggers of FCR were retained. However, one item "I am afraid of cancer recurrence" was indeed an item of the "severity" factor in the origiwal scale. Based on the assumption that experier nal scale. Based on the assuption that experiencing fear may be a trigger for FCR and as its factor loading is high enough, this item was decided to be include in the "triggers" factor. Indeed, this situation conform to Albert Bandura’s Reciprocal Determinism Principle of Social Cognitive Theory, where it is postulated that the internal factors like expectations and beliefs also shape emotions and behavior.[28] Besides, this can be explained by Becks's Cognitive Model that suggests that and trigger one another.[29]

The second factor of the scale, which consisted of two items was also named as "functioning impairments" as these two items were exactly those in the original "functioning impairments" subscale, which however had four more related items. These remaining four items, on the other hand, were loaded to the "quality of life" factor, and this situation is discussed within that factor later.

When we look at the third factor, it was observed that one of the items came from the "insight" factor of the original scale and the remaining items were from the "severity" factor. After carefully analyzing the content of these items, it seemed possible to consider them as metacognitions with respect to cancer recurrence. Thus, this newly generated factor in the Turkish version was named as "recurrence-related meta-cognitions." For example, the item 28 that was originally in the "insight" factor and the items 15-17 that were originally in the "severity" factor, represent metacognitive thinking re"led to cancer recursence, that is, thoughs on cancer in the components suggested in

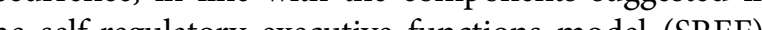
This model proposes that cognitive attention syndrome, which consists of self-focused attention, anxiety, attention bias against rumination and threat information, and maladaptive coping behavior (suppression, avoidance, minimizing) is the major source of maintenance in distressing emotions. There are research findings that suggest FCR is also alleviated and maintained as a function of cognitive attention syndrome descibed in SREF [1] 
When considering the fourth factor that consisted of five items, four of the items were from the "psychological distress," whereas item 34 was in the "coping strategies" factor of the original scale. Together with these five items, there seems to have emerged a new structure where all the statements are thought to represent specifically emotion-focused strategies to cope with FCR (see Table 1), the emotional responses of people against stressful conditions to manage such people ag [30] The "emotion. focued coping this factor

With respect to the fifth factor, while some of the items of this factor originally took place in "insight" factor (See items 29-30 in Table 1), the rest were (See items 24-26 in Table 1) in the "functioning impairments" subscale of the original version. It is thought that it would be appropriate to name this factor as "quality of life" considering that the new structure includes physical, mental, and social aspects of quality flife, as described by the World Health Organization (WHO).[31] In addition, when we view W the factor, as there are items like "I think I worry more about the possibility of cancer recurrence more than other people who have been diagnosed with cancer" that are specific to cancer, it can be proposed that the factor, in a sense, provides a quality of life measure specific to FCR.

To summarize, as a result of the factor analysis of the Turkish version of FCRI, three of the original "ubscales namely the "triggers" "functioning impair"coping stategies" " feened to be " mencerved in the Turkish version. Three new structures called as "recurrence-related meta-cognitions" "emotion-based coping strategies," and "quality of life" emerged from the differing loads of the original items. This resulted in the extinction of three original factors of "reassurance," "severity," and "psychological distress." However some items of these subscales were loaded under different factors in the Turkish version. Nevertheless, as to CFA, where it has been observed that the new version fit the data bett suggested that the Turkish version of FCRI has an acceptable factor structure.

Within the scope of concurrent validity of FCRI, when the relation of FCRI total score and PHQ-SADS and IES-R was considered, as expected, a moderate to high level of relation was observed between "intrusion" subscale of IES-R and "anxiety" and "depression" subscales of PHQ-SADS.[9] This finding is also in compliance with the fact that FCRI has been developed based havioral formulation, as stated in the literature.[15,16] The low level of correlation between FCRI total score and its subscales with "avoidance" subscale of IES$\mathrm{R}$, however, conflicts with the unique findings of the original study in which the scale has been developed. This may result from the fact that the "severity" factor no longer takes place as a distinct factor in the Turkish version. Together with the dismissal of the "reassurance" factor it may be suggested that the degree of FCR in the participants of this study is not at a clinical level. the participants of evel in this study in terms of the mean scores, it turns out to be higher than that in the original study [9] and in other studies wher fear of recurrence was generally observed to be below the mean.[6] But as there are no criteria to further evaluate this observation within this study, it needs to be investigated in further studies where the FCR levels of extreme groups can be compared in terms of, for example, health anxiety. As a final remark, the "'voidance" subscale of IES-R revealed a low value of interna consistency in this study, which denotes that these correlation values should be interpreted cautiously.

Our research has several limitations. The most important limitation is that a great majority of the participants answered the scale with the help of the researcher, although it was a self-administered test. It was decided to implement this method in accordance with the preferences of the participants. Besides, due to the difficulty of reaching the patient population in limited time, collecting some of the data via an online method is another limitation of the research. Howeve as no significant difference was observed between the mean total FCRI score as a function of type of administration, it can be concluded that the difference in the type of administration did not have a significant effect on the results. Another limitation is that the vast majority of participants were patients with breast cancer. This situation requires cautiousness while generalizin the results for other cancer types and male sex as it also led to an inequality in the sex frequency. Neverheless, this limitaion of the study was attempted to pted to hepeating most of the analysis within this breast cancer subsample where the results revealed almost the same tendency as observed in the whole sample. This can be accepted as an evidence for the generic property of FCRI. Indeed, the patients with breast cancer in the sample in the original study also outweighed the other cancer types. [9] However, further study for cross validation of these results via different cancer types may be employed. Another limitation is that no criteria that will provide a cutoff point to differentiate clinical FCR and nonclinical FCR has been included in the scale. According to various criteria, further studies are required for determining clinical FCR cutoff points. Finally, because of the difficulty in finding experts who have a command over French, the English version was adapted instead of the original French version. Although it is known that this situation is a limitation, it is considered that this limitation might have been eliminated partly by the fact that the English version has a high level of validity and reliability, similar to those of the French version. Despite the above mentioned limitations, it was ob-
served that the Turkish version of FCRI had a factor served that the Turkish version of FCRI had a factor
structure that was in compliance with the literature structure that was in compliance with the literature,
that is, its internal consistency and correlations with the structures were as expected and at an acceptable level. Due to these features, FCRI may be a tool that contributes to research that will be performed in the field as it evaluates FCR in a multidimensional manner. In future studies. FCR and the effects of cultural In fur examined via qualitative studies, and additionally the relationship of psychopathological variables such as health anxiety and personality patterns with FCR should be evaluated.

\section{Appendix}

The Turkish version of the items by the factors:

Triggers-Tetikleyiciler

2 Doktorumla veya baska bir sağlık profesyoneli ile bir randevu

3 Tibbi tetkikler (örneğin; ylllık check-up, kan tahlilleri, röntgenler)

5 Hasta birini görmek ya da hasta biri hakkında haber almak

Kanser veya hastalı hakkındaki televizyon programları veya gazete yazıları

Bir cenazeye gitmek ya da gazetenin ölüm ilanlar bölümünü okumak

10 Kanserin nüksetmesinden korkuyorum

Functioning Impairments-Fonksiyonel Bozulma-

22 Sosyal ya da boș zaman faaliyetlerimi ( Örneğin geziler, spor ve seyahat)

3 İs ya da günlük faaliyetlerimi

Recurrence-Related Meta-cognitions Nükse İlişkin Üst-bilişler

15 Kansernüksihtimalininekasarsıkdüşünüyorsunuz? 16 Kanser nüks ihtimali hakkında düsünmeye günde ne kadar vakit harciyorsunuz?

$17 \mathrm{Ne}$ kadar zamandır nüks ihtimali hakkında düşünmektesiniz?
28 Kansernüks ihtimali hakkında așırıendișelendiğimi hissediyorum.

Emotion-Focused Coping Strategies-Duygu Odakh Baş Etme Stratejile

19 Uzuntü, cesaret kırılması ya da hayal kırıklı̆

20 Hüsran/engellenmişlik, kızgınlık veya öfke

18 Endişe, korku veya kaygı

1 Çaresizlik veya teslimiyet

34 Dikkatimi dağıtmaya çalıșırım (Örn. ceşitli aktiviteler yaparım, televizyon izlerim, okurum, çalışırım)

Quality of Life-Yaşam Kalitesi

26 Ruh halim ya da duygu durumum

27 Genel olarak yaşam kalitemi

5 Gelecek ile ilgili planlar yapma ya da yaşam hedefleri koyma becerimi

24 Eşim/sevgilim, ailem ya da yakın olduğum insanlarla olan ilişkilerimi

30 Sanırım kanser nüks ihtimali hakkında kanser teshisi konmus diğer insanlardan daha fazla endișeleniyorum.

Acknowledgements: The authors would like to thank Pro Dr. Fuat Hulusi DEMIRELLİ for his invaluable supervision in sampling criteria and data collection.

Peer-review: Externally peer-reviewed.

Conflict of Interest: The authors declare that there is no conflict of interest.

Authorship contributions: Concept - A.E.; Design - A.E H.O.S.B.; Supervision - H.Ö.S.B.; Materials - A.E., H.Ö.S.B Data collection \&/or processing - A.E.; Analysis and/or interpretation - A E E H.ÖS $B_{,}$Literature search - A.E. Writing - A.E., H.Ö.S.B.; Critical review - H.Ö.S.B.

\section{References}

1. Butow PN, Fardell J, Smith A. Fear of cancer recurrence: an overview and Australian perspecive. Cancer Forum 2015;39(2):95-100.

2. Gültekin M, Boztaş G. Türkiye kanser istatistikleri. Sağlık Bakanlığı Türkiye Halk Sağlğ̆ 1 Kurumu 2014;43(36).

3. Ferlay I, Soerjomataram I, Dikshit R, Eser S, Mathers C, Rebelo M, et al. Cancer incidence and mortality worldwide: sources, methods and major patterns in GLOBOCAN 2012. Int J Cancer 2015;136(5):E35986.

Özkan S, Armay Z. Psiko-Onoloji. İstanbul: Novartis Oncology; 2007. p. 71-114,135-151

5. Vickberg SM. The Concerns About Recurrence Scale (CARS): a systematic measure of women's fears about 
the possibility of breast cancer recurrence. Ann Behav Med 2003;25(1):16-24.

6. Simard S, Thewes B, Humphris G, Dixon M, Hayden $\mathrm{C}$, Mireskandari S, et al. Fear of cancer recurrence in adult cancer survivors: a systematic review of quantitative studies. J Cancer Surviv 2013;7:300-22.

7. Lebel S, Ozakinci G, Humphris G, Thewes B, Prins J, Dinkel A, et al. Current state and future prospects of research on fear of cancer recurrence. Psychooncology 2017;26(4):424-7.

8. Glynne-Jones R, Chait I, Thomas SF. When and how to discharge cancer survivors in long term remission from follow-up: the effectiveness of a contract. Clin Oncol (R Coll Radiol) 1997;9(1):25-9.

9. Simard S, Savard J. Fear of Cancer Recurrence Inventory: development and initial validation of a multidimensional measure of fear of cancer recurrence. Support Care Cancer 2009;17(3):241-51.

10. Simard S, Savard J. Screening and comorbidity of clinical levels of fear of cancer recurrence. J Cancer Surviv 2015;9(3):481-91.

11. Thewes B, Butow P, Zachariae R, Christensen S, Simard $S$, Gotay C. Fear of cancer recurrence: a systematic literature review of self-report measures. Psychooncology 2012;21(6):571-87.

12. Thewes B, Bell ML, Butow P, Beith J, Boyle F, Friedlander $\mathrm{M}$, et al. Psychological morbidity and stress but not social factors influence level of fear of cancer recurrence in young women with early breast cancer: results of a cross-sectional study. Psychooncology 2013;22(12):2797-806.

13. Roth A, Nelson CJ, Rosenfeld B, Warshowski A, O'Shea $\mathrm{N}$, Scher $\mathrm{H}$, et al. Assessing anxiety in men with prostate cancer: further data on the reliability and validity of the Memorial Anxiety Scale for Prostate Cancer (MAX-PC). Psychosomatics 2006;47(4):340-7.

14. Simard S, Savard J, Ivers H. Fear of cancer recurrence: specific profiles and nature of intrusive thoughts. J Cancer Surviv 2010;4(4):361-71.

15. Lee-Jones C, Humphris G, Dixon R, Hatcher MB. Fear of cancer recurrence-a literature review and proposed cognitive formulation to explain exacerbation of recurrence fears. Psychooncology 1997;6(2):95-105.

16. American Psychiatric Association: Diagnostic and Statistical Manual of Mental Disorders. 4th ed. Washington: American Psychiatric Association; 1994.

17. Lebel S, Simard S, Harris C, Feldstain A, Beattie S, McCallum M, et al. Empirical validation of the English version of the Fear of Cancer Recurrence Inventory. Qual Life Res 2016;25(2):311-21.

18. Weiss DS, Marmar CR. The impact of event scale - revised. In: Wilson JP, Keane TM, editors. Assessing psychological trauma and PTSD. New York: Guilford Press; 1997. pp. 399-411.

19.Zigmond AS, Snaith RP. The hospital anxiety and depression scale. Acta Psychiatr Scand 1983;67(6):36170.

20. Kroenke K, Spitzer RL, Williams JB, Löwe B. The Patient Health Questionnaire Somatic, Anxiety, and Depressive Symptom Scales: a systematic review. Gen Hosp Psychiatry 2010;32(4):345-59.

21. Yazici Güleç M, Güleç H, Simşek G, Turhan M, Aydin Sünbül E. Psychometric properties of the Turkish version of the Patient Health Questionnaire-Somatic, Anxiety, and Depressive Symptoms. Compr Psychiatry 2012;53(5):623-9.

22.van den Beuken-van Everdingen MH, Peters ML, de Rijke JM, Schouten HC, van Kleef M, Patijn J. Concerns of former breast cancer patients about disease recurrence: a validation and prevalence study. Psychooncology 2008;17(11):1137-45.

23. Çorapçıŏlu A, Yargıç İ, Geyran P, Kocabaşoğlu N. Olayların etkisi ölçeği. In IES-R) Türkçe versiyonunun geçerlilik ve güvenilirliği. New Symposium 2006;44:14-22.

24. Şimşek ÖF. Yapısal eşitlik modellemesine giriş: Temel ilkeler ve LISREL uygulamaları. Ankara: Ekinoks; 2007. p. 315-37.

25. Hu LT, Bentler PM. Cutoff criteria for fit indexes in covariance structure analysis: Conventional criteria versus new alternatives. Structural Equation Modeling 1999;6:1-55.

26. Marsh HW, Hau K, Wen Z. In search of golden rules: comment on hypothesis-testing approaches to setting cutoff values for fit indexes and dangers in overgeneralizing $\mathrm{Hu}$ and Bentler's (1999) findings. Structural Equation Modeling 2004;11:320-41.

27. Sürgevil O, Tolay E, Topoyan M. Yapısal Güçlendirme ve Psikolojik Güçlendirme Ölçeklerinin Geçerlilik ve Güvenirlik Analizleri. Journal of Yasar University 2013;8(31):5371-91.

28. Bandura A. Social foundations of thought and action: a social cognitive theory. Englewood Cliffs, NJ: Prentice Hall; 1986.

29. Beck JS. Cognitive behavior therapy: Basics and beyond. Guilford Press; 2011.

30. Lazarus RS, Folkman S. Stress, appraisal and coping. New York: Springer; 1984.

31. Development of the World Health Organization WHOQOL-BREF quality of life assessment. The WHOQOL Group. Psychol Med 1998;28(3):551-8. 